\title{
Conversion of L-Tryptophan into Melatonin Is the Possible Action Pathway Involved in the Effect of L-Tryptophan on Antidepressant-Related Behavior in Female Rats: Analysis of the Influence of Treatment Duration
}

\author{
Sihame Ouakki ${ }^{1}$, Fatima Zahra El Mrabet ${ }^{{ }^{*}}$, Aboubaker El Hessni ${ }^{1}$, \\ Abdelhalem Mesfioui ${ }^{1}$, Paul Pévet ${ }^{2}$, Ali Ouichou ${ }^{1}$ \\ ${ }^{1}$ Laboratory of Genetics, Neuroendocrinology and Biotechnology, Unit of Nervous and Endocrine Physiology, \\ Faculty of Sciences, Université Ibn Tofail, Kenitra, Morocco \\ ${ }^{2}$ Institute for Cellular and Integrative Neurosciences, Strasbourg University, Strasbourg, France

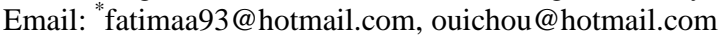

Received June 27, 2013; revised July 28, 2013; accepted August 1, 2013

Copyright (c) 2013 Sihame Ouakki et al. This is an open access article distributed under the Creative Commons Attribution License, which permits unrestricted use, distribution, and reproduction in any medium, provided the original work is properly cited.

\begin{abstract}
The aim of this study was to determine the effect of pharmacological doses of melatonin (MEL) and L-tryptophan (L-TRP) on depression-like behavior in female rats submitted to the forced swimming test (FST) after 2, 4, 6 or 8 weeks of treatment. This will allow exploring the different mechanisms of L-TRP actions particularly that due to its conversion into MEL. For this purpose, four groups of 24 rats each were constituted; (Group 1: Control): received saline solution $\mathrm{NaCl}$ (0.9\%), (Group 2: MEL4): received $4 \mathrm{mg} / \mathrm{Kg}$ of MEL, (Group 3: L-TRP4): received $4 \mathrm{mg} / \mathrm{Kg}$ of L-TRP and (Group 4: L-TRP20): received $20 \mathrm{mg} / \mathrm{Kg}$ of L-TRP. Animals of each group were distributed on 4 subgroups of 6 rats submitted to different time treatments. The duration of immobility (TIM) and struggling period (TST) of rats in FST were measured after 2, 4, 6 and 8 weeks of drug treatment and the effects of MEL and L-TRP were compared. Chronical administration of different doses of MEL or L-TRP failed to induce any anti-depressant activity in rats subjected to FST after 2 weeks of treatment. However, after 4 weeks, daily administration of MEL at $4 \mathrm{mg} / \mathrm{Kg}$ significantly reduced the immobility period and enhanced struggling time. After 6 weeks, MEL at $4 \mathrm{mg} / \mathrm{Kg}$ and L-TRP at $20 \mathrm{mg} / \mathrm{Kg}$ were both effective in reducing immobility and increasing struggling movement, their effects being statistically comparable. All treatments were able to significantly reduce immobility time and increase struggling duration after 8 weeks, but L-TRP at $4 \mathrm{mg} / \mathrm{Kg}$ was less potent than MEL and L-TRP at $20 \mathrm{~g} / \mathrm{Kg}$. The antidepressant-like activity of L-TRP was dose and time dependent, and that of MEL was time dependent. In conclusion, the study showed that at pharmacological doses, MEL and L-TRP have anti-depressant action, and such effect is dependent on time treatment; MEL is more effective than L-TRP. In conclusion, L-TRP, through MEL, 5-HT or by itself could modulate aminergic neurotransmission in the different brain areas to ensure its behavioral effects.
\end{abstract}

Keywords: Melatonin; L-Tryptophan; Depression; Forced Swimming; Immobility; Struggling; Female Rats

\section{Introduction}

Melatonin (MEL) is a methoxyindole secreted mainly, but not exclusively by the pineal gland since pinealectomy abolishes its synthesis and its rhythmic pattern release. The initial step of MEL biosynthesis involves the uptake of L-tryptophan (L-TRP) from the circulation into the pinealocytes, followed by its conversion into 5-hydroxytryptophan by TRP-hydroxylase. Further decarboxy-

"Corresponding author. lation by L-aromatic aminoacid decarboxylase leads to serotonin (5-HT) formation. 5-HT is first acetylated by $\mathrm{N}$-acetyltransferase (NAT), which is probably the ratelimiting step, and then methylated by hydroxyindole orthomethyltransferase (HIOMT) to MEL. Characteristically, pineal MEL is secreted in a circadian manner with high levels occurring in all studied species at night. In mammals, the MEL rhythm is generated by an endogenous circadian clock in the suprachiasmatic nucleus (SCN) of the hypothalamus, which is entrained by the light/dark 
cycle to the $24 \mathrm{~h}$ [1]. As MEL is a lipophilic compound, it freely diffuses through biological membranes and readily crosses the blood brain barrier to attain the central nervous system in order to ensure multiple and various physiological and behavioral actions [2].

Among these functions, MEL is involved in the control of circadian and seasonal rhythms [3,4], sleep regulation [5], immune function [6], growth inhibition of malignant cells [7], blood pressure regulation [8], retinal functions [9], free radical scavenging and other antioxidant actions [10] and modulation of mood disorders and affective behavior [11]. Many of these effects are mediated by MEL receptors ( $\mathrm{MT}_{1}$ and $\left.\mathrm{MT}_{2}\right)$ which are widely distributed in the brain and peripheral organs [12].

The relationship between MEL levels, pineal function, and mood or psychiatric disorders is strengthened by some evidences based on clinical observations in Humans and experimental administration of MEL in animals. Thus, in Humans, nocturnal MEL levels are low in subjects with major depressive and panic disorder $[11,13]$. Some healthy individuals with a dysthymic disposition (mild or episodic depression) also have lower-than-normal nocturnal MEL levels [14] as well as subjects with melancholic depression [15]. In depressed patients, it has also observed a phase advance of their circadian rhythms of MEL relative to their sleep and other circadian rhythms [16]. In rodents, several studies indicate the involvement of pineal gland and MEL in the regulation of depression. In rats we have recently reported that abolition of endogenous MEL by pinealectomy may exacerbate depression-like behaviors [17] as shown in siberian hamster, whose maternal pinealectomy increases also depressivelike responses [18]. This depressive effect of pinealectomy is reversed by MEL administration which improves behavioral response of animals, indicating that MEL presents some characteristics of antidepressant drug action $[17,19]$. In mice, it has been also reported that daily administration of exogenous MEL is able to counteract changes in despair indexes induced by the unpredictable chronic mild stress, especially the coat state, grooming behaviour and corticosterone levels [20].

As it's mentioned above, MEL is a derivative of serotonin, which in turn is derived from the essential amino acid L-TRP. Unlike MEL, little is known about the effect of chronic administration of L-TRP. This aminoacid plays an instrumental role in balancing mood and sleep patterns and may be of some benefit in the treatment of some psychiatric disorders since changes in TRP metabolism under stress are assumed to be a risk factor for major depression [21]. Some observations show a direct association between TRP deficiency or depletion and pathological and psychiatric disorders in Humans. Thus, TRP depletion causes a rapid lowering of mood in normal males [22], induces antidepressant-like effects [23] and reverses antidepressant-induced remission [24]. It also produces depressive symptoms in remitted depressive patients [25], whereas in healthy subjects, no or only modest effects are found [26].

The involvement of MEL in mediating of TRP action is strongly suggested in many reports as in hypnotic function and affective and sedative action of TRP [23,27,28]. In support of this, TRP administration or a high plasma ratio between TRP and large neutral amino acids enhances brain TRP levels, and accelerates 5-HT and MEL synthesis. Indeed, administration of TRP increases the availability of 5-HT in the brain of different species [29], and then immediately stimulates the synthesis of MEL increasing its levels in plasma [30]. Also, oral supplementation of TRP causes a rapid and dose-dependent elevation of circulating MEL [31]. Inversely, acute TRP depletion decreases free and total plasma TRP levels and leads to decrease of diurnal 5-HT and nocturnal MEL secretion [32].

However, the literature influence of chronic effects of L-TRP, extending over several weeks on affective behavior, is not sufficiently explored, studies are generally interested in acute administration, experimental depletion or oral supplementation of L-TRP. In the present study, we 1) examine the effect of chronic administration of MEL (4 mg/kg b.w.) and L-TRP (4 and $20 \mathrm{mg} / \mathrm{kg}$ b.w.) on depression-related behavior in female rats and 2) analyze the time dependence by comparing these effects during 2, 4, 6 and 8 weeks of treatment. This will allow us to explore the different mechanisms of L-TRP actions particularly that due to its conversion into MEL.

\section{Materials and Methods}

\subsection{Animals}

This experimental study was performed on female Wistar rats initially weighing $(100 \pm 20) \mathrm{g}$. Animals were housed by six in cage (36 cm long, $20 \mathrm{~cm}$ wide and $15 \mathrm{~cm}$ high). All rats were maintained under LD 12/12 (12 h Light/12h Darkness) and at a standard temperature of $(21 \pm 1){ }^{\circ} \mathrm{C}$. Water and food were provided ad libitum. At the beginning of experiments, the colony room was transferred in long photoperiod LD: 16/8 (16 h Light/8h Darkness).

\subsection{Experimental Procedure}

Ninety sex animals used in the present experiment were divided into 4 groups of 24 animals as following: (group 1: control): rats injected subcutaneously, once daily with saline solution $\mathrm{NaCl}(0.9 \%)$ as vehicle containing $5 \%$ ethanol, (group 2: MEL4): rats injected with $4 \mathrm{mg} / \mathrm{Kg}$ of MEL (group 3: L-TRP4): rats injected with $4 \mathrm{mg} / \mathrm{Kg}$ of L-TRP and (group 4: L-TRP20): rats injected with 20 mg/Kg of L-TRP. MEL (Sigma Lot No. 112K0998 France) 
and L-TRP (Sharlau, ServiChim, Casablanca, morocco) were dissolved in 5\% ethanol. All injections were made approximately at 4:00 pm (2 h before dark phase). Each group was subdivided on 4 experimental subgroups of 6 animals designed to compare emotional behavior of rats after 2, 4, 6 and 8 weeks of treatment. At the end of each period of treatment, the rats were subjected to the Porsolt forced swimming-induced behavioral despair test (FST) to study the effect of drugs on duration of immobility (TIM) and struggling period (TST).

\subsection{Depression-Like Measurement by Forced Swimming Test}

The forced swimming test (FST) is a maze usually used to assess the depressive-like behavior [33,34]. Swimming sessions were conducted by placing the rat in individual glass cylinders (height: $50 \mathrm{~cm}$; diameter: $30 \mathrm{~cm}$ ) containing $30 \mathrm{~cm}$ of water at $\left(23^{\circ} \mathrm{C} \pm 2^{\circ} \mathrm{C}\right)$. During the session, rats were forced to swim for $5 \mathrm{~min}$ and the duration of immobility was measured. The latency to the first bout of immobility was also recorded starting immediately after placing the rats in the cylinder. A rat was judged immobile when it ceased all active behaviors (i.e. struggling, swimming and jumping) and remained passively floating or making minimal movements necessary to maintain the nostrils above water. High percent time floating is interpreted as an increased depressive-like response [33,35].

\subsection{Quantitative Presentation of Results}

The animals of control groups showed a relative variation in their behavior activity over the time in FST. To eliminate this variation, the activity of control group for each time was considered as the reference level expressed as $100 \%$ of activity. To evaluate the effect of various treatments, the individual response of animals of treated groups were calculated relative to the mean control group activity, i.e. $100 \%$. Thus, the intensity of the response of animals of treated groups was established as decreased or increased individual activities relative to the basal level for each time.

\subsection{Statistical Analysis}

All data are expressed as the means \pm standard error of the means (S.E.M.). To determine the differences between experimental groups statistical analysis was performed by analysis of variance (ANOVA) 1st/2nd order followed by a post-hoc tests (Fisher LSD) or Student test " $\boldsymbol{t}$ ". Differences were considered significant when $\mathrm{p}<$ 0.05 , very significant when $p<0.01$ and highly significant when $\mathrm{p}<0.001$.

\section{Results}

\subsection{Effect of MEL and L-TRP on Depression-Like Behavior}

\section{Effect on immobility time (TIM) (Figure 1):}

After 2 weeks of treatment immobility time (TIM) was not affected by MEL (NaCl/MEL4: $(\mathrm{p}=0.19>0.05)$ or L-TRP [NaCl/L-TRP4: $(p=0.10>0.05)$ and $\mathrm{NaCl} / \mathrm{L}-$ TRP20 ( $\mathrm{p}=0.56>0.05)]$. After 4 weeks, MEL, but not different doses of L-TRP, significantly decreased TIM with comparison to control group (NaCl/MEL4: ( $<<$ 0.05). TIM of L-TRP20 was lower than control group even if the difference was not significant $(\mathrm{NaCl} / \mathrm{L}-\mathrm{TRP} 20$ : $\mathrm{p}>0.05$ ). No significant difference was observed between L-TRP4 and L-TRP20 (L-TRP4/L-TRP20: p > 0.05).

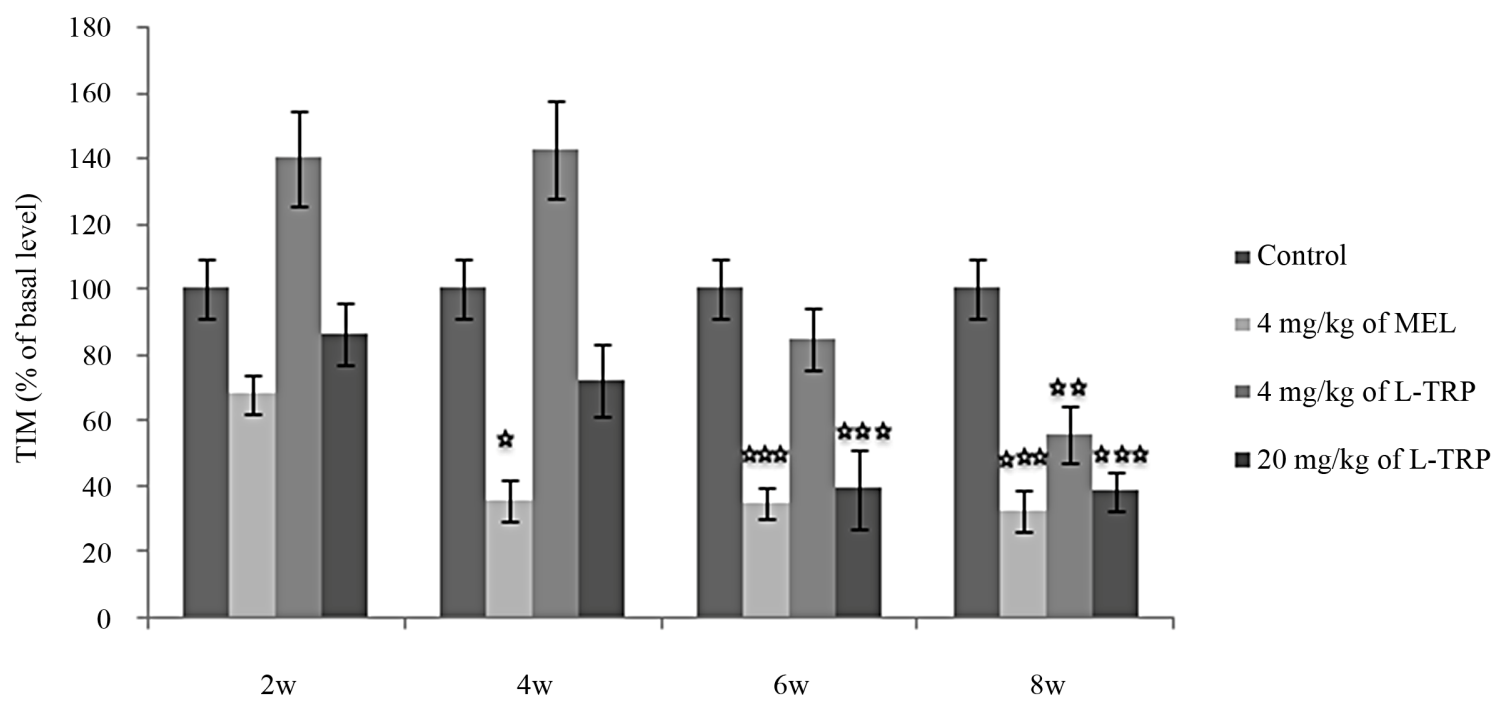

Figure 1. Immobility time (TIM) in forced swimming test of rats treated with $4 \mathrm{mg} / \mathrm{kg} \mathrm{of} \mathrm{MEL,} \mathrm{(4} \mathrm{or} \mathrm{20)} \mathrm{mg/kg} \mathrm{of} \mathrm{L-TRP)} \mathrm{or}$ $0.9 \%$ of $\mathrm{NaCl}$ during 2, 4, 6 or 8 weeks. Results are expressed as Mean \pm (S.E.M.) of values activities of 6 animals in each group. ${ }^{*} \mathrm{p}<0.05,{ }^{* *} \mathrm{p}<0.01,{ }^{* * *} \mathrm{p}<0.001$. 
After 6 weeks, both MEL and L-TRP at $20 \mathrm{mg} / \mathrm{Kg}$ significantly and similarly reduced TIM [(NaCl/MEL: $\mathrm{p}=$ $0.00005<0.001)$; $(\mathrm{NaCl} / \mathrm{L}-\mathrm{TRP} 20: \mathrm{p}=0.0001<0.001)$ ]. In contrast, L-TRP at $4 \mathrm{mg} / \mathrm{Kg}$ didn't affect this parameter $(\mathrm{NaCl} / \mathrm{L}-\mathrm{TRP} 4: \mathrm{p}=0.21>0.05)$. No significant difference was noted between L-TRP4 and L-TRP20: (LTRP4/L-TRP20: $p>0.05)$. After 8 weeks, all treated groups showed a TIM significantly lower than control group [(NaCl/MEL4: $\mathrm{p}=0.00004<0.001)$; $(\mathrm{NaCl} / \mathrm{L}-$ TRP4: $(\mathrm{p}=0.002<0.01) ;(\mathrm{NaCl} / \mathrm{L}-\mathrm{TRP} 20(\mathrm{p}=0.0001<$ 0.001)]; the effects of MEL and TRP at $20 \mathrm{mg} / \mathrm{kg}$ being significantly comparable.

Effect on struggling time (TST) (Figure 2):

Similarly, after 2 weeks, no significant difference was noted between all groups with regard to struggling time (TST): [(NaCl/MEL4: $(\mathrm{p}=0.36>0.05)$; $(\mathrm{NaCl} / \mathrm{L}-\mathrm{TRP} 4$ : $\mathrm{p}=0.88>0.05)$; $(\mathrm{NaCl} / \mathrm{L}-\mathrm{TRP} 20: \mathrm{p}=0.36>0.05)]$ respectively. After 4 weeks, MEL, but not different doses of L-TRP, significantly increased TST with comparison to control group [(NaCl/MEL4: $\mathrm{p}=0.01<0.05)$; $(\mathrm{NaCl} /$ L-TRP4: $\mathrm{p}=0.89>0.05) ;(\mathrm{NaCl} / \mathrm{L}-\mathrm{TRP} 20: \mathrm{p}=0.18>$ 0.05)]. After 6 weeks, both MEL and L-TRP at $20 \mathrm{mg} / \mathrm{Kg}$, but not L-TRP at $4 \mathrm{mg} / \mathrm{Kg}$, significantly enhanced TST [(NaCl/L-TRP4: $\mathrm{p}=0.02<0.05) ;(\mathrm{NaCl} / \mathrm{L}-\mathrm{TRP} 4:(\mathrm{p}=$ $0.46>0.05) ;(\mathrm{NaCl} / \mathrm{L}-\mathrm{TRP} 20: \mathrm{p}=0.004<0.01)]$. After 8 weeks, different treatement were all able to increase significantly TST: [(NaCl/MEL4: $\mathrm{p}=0.007<0.01)$; (NaCl/L-TRP4: $\mathrm{p}=0.018<0.05)$; $(\mathrm{NaCl} / \mathrm{L}-\mathrm{TRP} 20: \mathrm{p}=$ $0.0006<0.001)]$; the effects of MEL and TRP being significantly comparable.

\subsection{Effect of Time Treatment by MEL and L-TRP on Depression-Like Behavior}

For the control group, no significant difference was observed in immobility and struggling behavior over the time; the values of TIM and TST remaining comparable after 2, 4, 6 and 8 weeks of treatment.

Effects of MEL at $4 \mathrm{mg} / \mathrm{kg}$ over the time (Figures 3(a) and (b)):

MEL decreased TIM, since the TIM values obtained after 4, 6 and 8 weeks of treatment with MEL at $4 \mathrm{mg} / \mathrm{kg}$ were significantly lower than after 2 weeks $[(2 \mathrm{w} / 4 \mathrm{w}$ : $\mathrm{p}<$ 0.001); (2w/6w: $\mathrm{p}<0.001)$; (2w/8w: $\mathrm{p}<0.001)$ ]. In addition, the TIM observed after 6 and 8 weeks of treatment were significantly lower than after 4 weeks [ $(4 \mathrm{w} /$ 6w: $\mathrm{p}<0.05)$; (4w/8w: $\mathrm{p}<0.001)$ ] and this TIM after 8 weeks of treatment was significantly lower than after 6 weeks (6w/8w: $\mathrm{p}<0.001)$. Inversely, MEL enhanced TST, and its effects increased proportionally with number of weeks [(2w/6w: p < 0.001); (2w/8w: p < 0.001); [(4w/6w: $\mathrm{p}<0.01)$; (4w/8w: $\mathrm{p}<0.001)(6 \mathrm{w} / 8 \mathrm{w}: \mathrm{p}<0.001)]$.

Effects of L-TRP at $4 \mathrm{mg} / \mathrm{Kg}$ over the time (Figures 4(a) and (b)):

The decrease of TIM under L-TRP treatment at $4 \mathrm{mg} / \mathrm{Kg}$ depended on the duration of treatment. The difference was more significant and the effect greater when the number of weeks between the compared groups is important [(2w/4w: $\mathrm{p}<0.05)$; (2w/6w: $\mathrm{p}<0.001)$; $(2 \mathrm{w} / 8 \mathrm{w}$ : $\mathrm{p}<0.001)]$. In addition, the TIM after 8 weeks of treatment was significantly lower than after 4 weeks (4w/8w: $\mathrm{p}<0.05$ ). With regard to TST, the effect obtained at 8

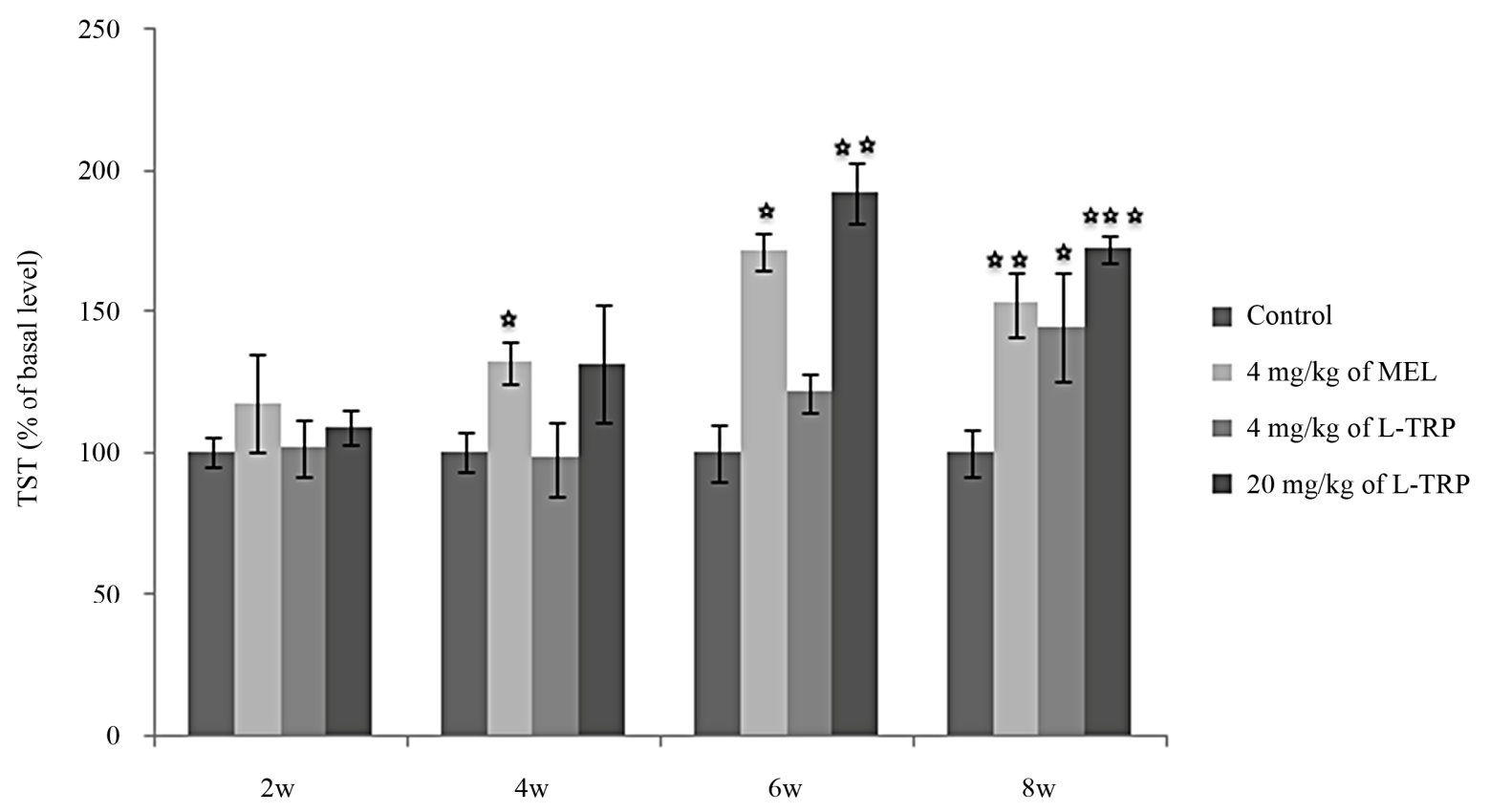

Figure 2. Struggling time (TST) in forced swimming test of rats treated with $4 \mathrm{mg} / \mathrm{kg} \mathrm{of} \mathrm{MEL,} \mathrm{(4} \mathrm{or} \mathrm{20)} \mathrm{mg/kg} \mathrm{of} \mathrm{L-TRP)} \mathrm{or}$ $0.9 \%$ of $\mathrm{NaCl}$ during 2, 4, 6 or 8 weeks. Results are expressed as Mean \pm (S.E.M.) of values activities of 6 animals in each group. ${ }^{*} \mathrm{p}<0.05,{ }^{* *} \mathrm{p}<0.01,{ }^{* * *} \mathrm{p}<0.001$. 


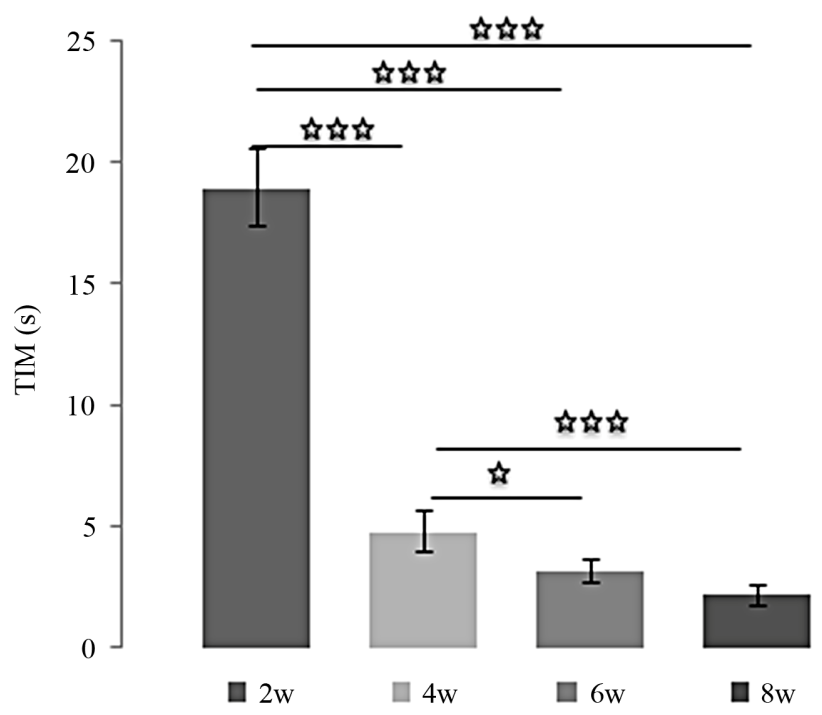

(a)

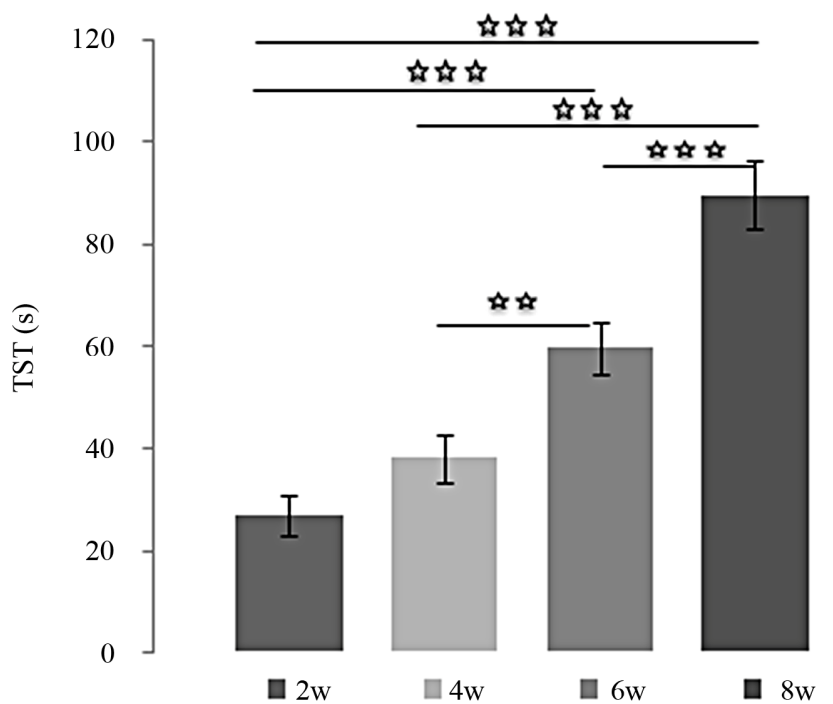

(b)

Figure 3. (a) Immobility time (TIM) and (b) Struggling time (TST) in forced swimming test of rats treated with $4 \mathrm{mg} / \mathrm{kg}$ of MEL during 2, 4, 6 or 8 weeks. Results are expressed as Mean \pm (S.E.M.) of activities of 6 animals in each group. Values at distal ends of horizontal bar differ, ${ }^{*} \mathrm{p}<0.05,{ }^{* *} \mathrm{p}<0.01,{ }^{* * *} \mathrm{p}<0.001$.

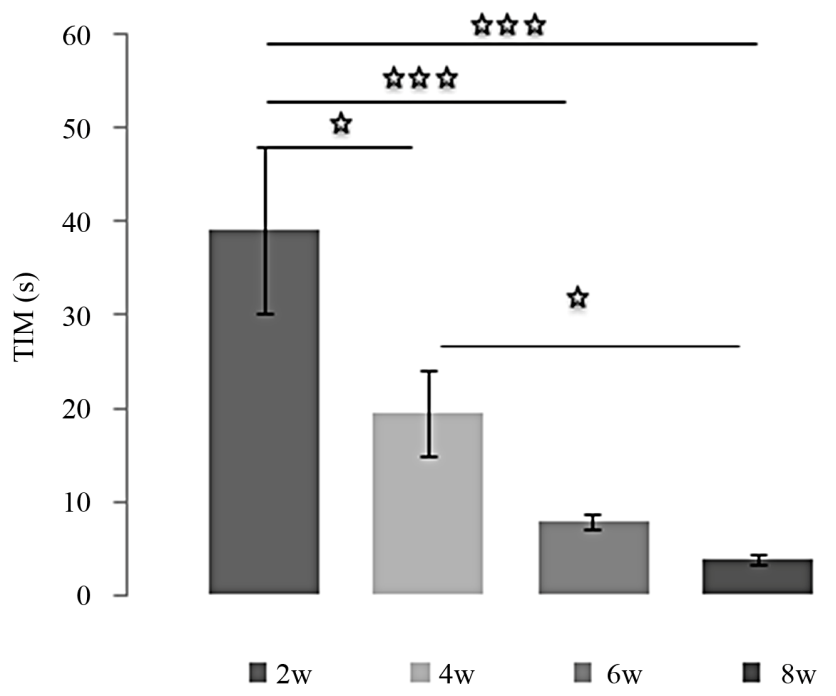

(a)

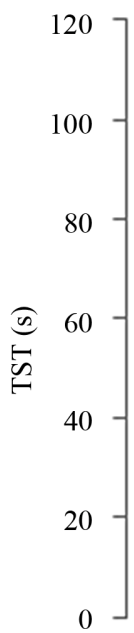

$\square 2 \mathrm{~W}$

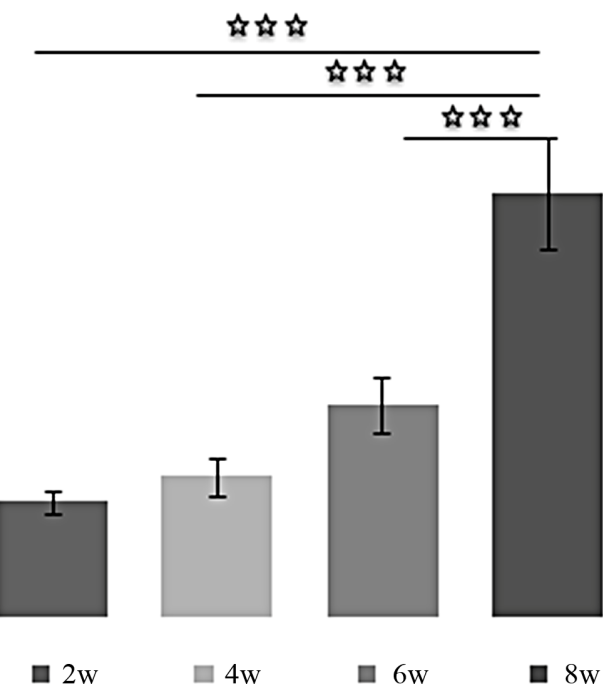

(b)

Figure 4. (a) Immobility time (TIM) and (b) Struggling time (TST) in forced swimming test of rats treated with $4 \mathrm{mg} / \mathrm{kg}$ of L-TRP during 2, 4, 6 or 8 weeks. Results are expressed as Mean \pm (S.E.M.) of activities of 6 animals in each group. Values at distal ends of horizontal bar differ, ${ }^{*} \mathrm{p}<0.05,{ }^{* *} \mathrm{p}<0.01,{ }^{* * *} \mathrm{p}<0.001$.

weeks was significantly higher compared to other times $[(2 \mathrm{w} / 8 \mathrm{w}: \mathrm{p}<0.001) ;(4 \mathrm{w} / 8 \mathrm{w}: \mathrm{p}<0.001)(6 \mathrm{w} / 8 \mathrm{w}: \mathrm{p}<$ $0.001)]$.

\section{Effects of L-TRP at $20 \mathrm{mg} / \mathrm{Kg}$ over the time (Figures} 5(a) and (b)):

The effects of L-TRP at $20 \mathrm{mg} / \mathrm{Kg}$ on TIM were very similar to those of MEL: [(2w/4w: $\mathrm{p}<0.001)$; $(2 \mathrm{w} / 6 \mathrm{w}$ : $\mathrm{p}$ $<0.001)$; (2w/8w: p < 0.001); (4w/6w: p < 0.001); $(4 \mathrm{w} /$ $8 \mathrm{w}: \mathrm{p}<0.001)]$. The same observation was made for the evolution of TST with time: [(2w/6w: $p<0.001)$; $(2 \mathrm{w} / 8 \mathrm{w}$ : $\mathrm{p}<0.001)$; [(4w/6w: $\mathrm{p}<0.001) ;(4 \mathrm{w} / 8 \mathrm{w}: \mathrm{p}<0.001)]$, except the difference between 6 and 8 weeks is not significant.

\section{Discussion}

The aim of this study was to investigate the influence of pineal indole MEL and its precursor L-TRP administration on 1) depressive-like behaviors in FST and 2) to analyze the evolution of their effects over the time. The comparison of L-TRP and MEL effects will allow us to explore the different action ways of L-TRP.

We found that in FST, rats injected by MEL or L-TRP 


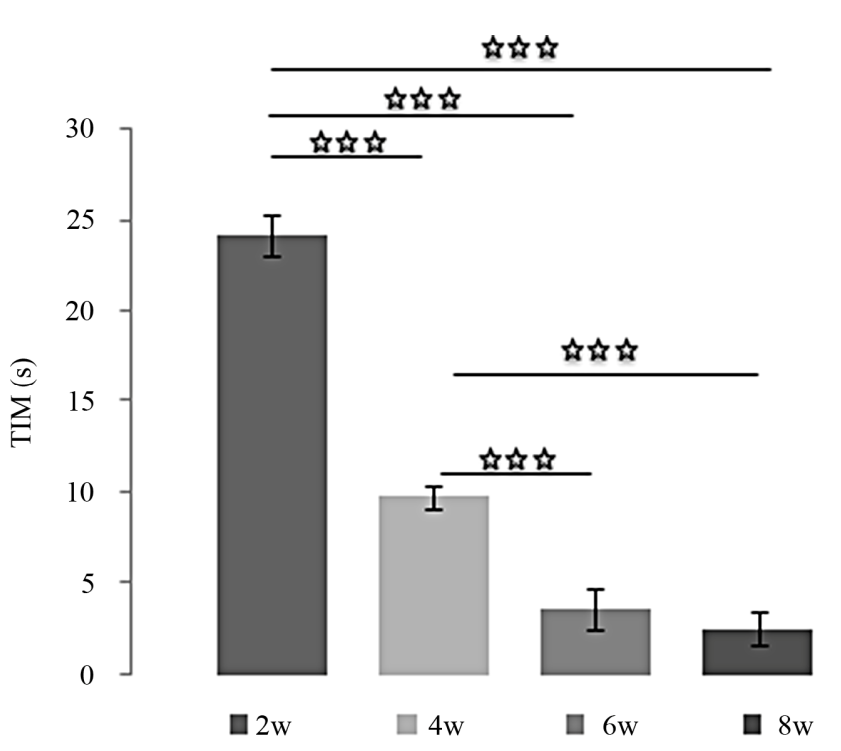

(a)

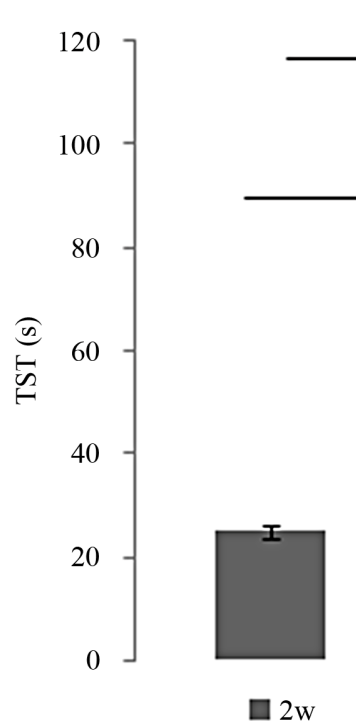

2w

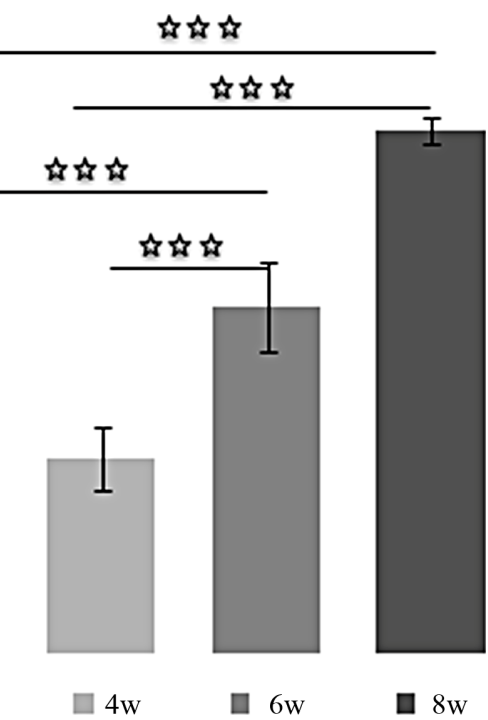

(b)

Figure 5. (a) Immobility time (TIM) and (b) Struggling time (TST) in forced swimming test of rats treated with $20 \mathrm{mg} / \mathrm{kg}$ of L-TRP during 2, 4, 6 or 8 weeks. Results are expressed as Mean \pm (S.E.M.) of activities of 6 animals in each group. Values at distal ends of horizontal bar differ, ${ }^{*} \mathrm{p}<0.05,{ }^{* *} \mathrm{p}<0.01,{ }^{* * *} \mathrm{p}<0.001$.

showed a low level of depressive-like behavior since the immobility time of treated animals was lower and struggling movements were higher and more frequent than control. These findings suggest that depression measurement is more sensitive to drug treatment since MEL and L-TRP administration interacted with depression provoking test situations. Consequently, MEL and L-TRP may exert antidepressive-like effects in this paradigm. In addition, the antidepressant-like action of both MEL and L-TRP was time-dependent and dose-dependent for L-TRP.

These results are in accordance with many reports on rodents in the literature and with our previous report in male and female rats $[17,19]$. This report showed that MEL administrated chronically in rats produced a real antidepressant power that is expressed in FST since it decreased TIM and enhanced TST. Similar result in both sexes of rats, showing that MEL decreased swimming in the FST, was previously observed by Brotto et al. [36]. In this sense, it has reported that in rats submitted to the same paradigm; low doses of MEL were able to decrease the immobility time, confirming antidepressant-like properties of the hormone [37]. Changes in despair index related, as the coat state, grooming behavior and corticosterone levels, were observed in mice submitted to chronic mild stress [20]. These indexes were counteracted by daily administration of exogenous MEL or imipramine a tricyclic antidepressant. Comparable results demonstrated that co-administration of MEL and imipramine exhibited an additive of their effects to reduce depression-like behavior in mice submitted to FST [38]. In rats and mice, MEL, in dose of $10 \mathrm{mg} / \mathrm{kg}$, significantly reduced the forced-swimming induced immobility period, per se, and also reserpine induced immobility [39]. In BALB/c and C57BL/6J mice, an antidepressant action of pharmacological doses of MEL was also shown in FST [40]. In addition to MEL, behavioral effects of several of ligands of MEL receptors were also reported. Indeed, it has been clearly demonstrated that in FSL rats [41] and in the transgenic mouse model [42] S20304 and agomelatine (S20098) exhibit hight antidepressive-like activity and show some characteristics of antidepressant drug action. As agomelatine is a $\mathrm{MEL}$ ( $\mathrm{MT}_{1}$ and $\mathrm{MT}_{2}$ receptors) agonist and selective serotonin (5-HT2C receptor) antagonist, it has been suggested that its antidepressant activity could be mediated by $\mathrm{MT}_{1}$ and $\mathrm{MT}_{2}$ receptor and/or 5-HT2C receptors [43]. Using MEL receptor antagonist, luzindole (N-0774), comparable results were obtained in mouse, emphasizing the antidepressant-like activity of the ligand by antagonizing the anxiogenic action of endogenous MEL [44,37]. The antidepressant effect of MEL in FST was totally suppressed by 5-HT2A/5-HT2C agonist in the amygdale suggesting the interaction of the hormone with central 5-HT neurotransmission [37]. Our results associated with those of the literature mentioned above strongly reassessed the potential of MEL as an antidepressant.

Moreover, we reported that like MEL, chronic administration of L-TRP was able to reduce immobility and to enhance struggling of animals in FST, L-TRP being less potent than MEL at the same dose. Indeed, after 4 weeks, $20 \mathrm{mg} / \mathrm{Kg}$ of L-TRP were necessary to obtain a comparable behavioral effect to MEL at $4 \mathrm{mg} / \mathrm{Kg}$, whereas LTRP at $4 \mathrm{mg} / \mathrm{Kg}$ required at least 6 and 8 weeks for inducing depressive-like effect. 
Unfortunately, in the literature, chronically effects of L-TRP have not been well investigated, studies are generally interested in acute TRP administration or depletion or oral supplementation. Our study has the advantage of following the TRP effect over several weeks. It is consistent with the report of Wong and Ong [23], reporting an antidepresssive-like effect of a single dose of TRP in mice, such effect is dose-dependent. In the same species, the reduction of immobility by TRP in Porsolt's swim test has been also reported suggesting that TRP has antidepressant-like properties [45]. In rats, the reduction of depression by L-TRP alone or in association with clomipramine [46] or fluoxetine [47] was clearly demonstrated. The present work is also in accordance with some studies using acute TRP depletion in association to depression-related behavior in rodents. Thus, Sprague Dawley rats, but not Brown Norway rats, showed more depression-related behavior after TRP depletion [48]. Rats submitted to L-TRP restriction displayed a significant increase of immobility counts in the FST [49]. Our results associated with those of the literature mentioned above clearly demonstrated a reduction in depression levels of the animals by pharmacological treatment of L-TRP whatever the experimental conditions and/or depression provoking situations.

To ensure its behavioral functions, L-TRP may cross the blood brain barrier, attain different areas of the brain and act by itself or by its conversion into MEL and/or 5-HT. The cerebral L-TRP amount not only depends on the absolute concentration of blood TRP but also the relative concentrations of these neutral that compete with TRP in the blood. Then the aminoacid will be picked up by pinealocytes but also serotonergic neurons. Under physiological conditions, fluctuations in brain L-TRP may sound on the metabolism of 5-HT and MEL in the brain. Indeed, the limiting enzyme, TRP-hydroxylase, is not saturated by its substrate. An increase in brain L-TRP therefore leads automatically, and to a certain extent, an increase in the rate of biosynthesis of 5-HT. The studies suggest that charge of L-TRP TRP hydroxylase is only saturated at 50\% [50,51]. For this reason, it has been suggested that the administration of L-TRP could, to some extent, stimulate the brain serotonergic melatoninergic activity and reduce some psycho-biological disorders associated with dysfunction of serotonergic and melatoninergic activities [52].

In this study, it's possible that L-TRP administration raises circulating MEL levels, which in turn could act on the central nervous system to regulate affective response. In support of this hypothesis: 1) MEL and L-TRP have comparable antidepressant-like properties; 2) TRP is the precursor of MEL and 3) MEL concentrations are affected by the amount of TRP available in the blood and brain [53]. Many studies reported indeed that TRP ad- ministration followed by an increase of MEL levels at all the times analyzed, this increase being greater in the dark period than in the light period. In rats, this increase was greater when the administration was at night than when it was made during the day [53,54]. Also, subchronic intake of TRP increases MEL levels in plasma and pineal over a 24-hour period, as well as advancing the peak of its synthesis [55]. Similar results were obtained by Cubero et al. [56] in ringdove, who observed a consequent augmentation in serum MEL levels after TRP injection or TRP intragastric administration to Wistar rats [57]. In man, infusions of TRP caused also significant massive elevation of plasma MEL levels both during the night and the day [58]. Nonetheless, it must be borne in mind that variations in MEL levels following TRP administration depend on several factors, including the amount administered, the time of administration, the number of doses, and the type of animal [59].

Moreover, several studies have shown that in humans, administration of L-TRP induced an increase in brain levels of TRP but also of 5-HIAA (50\%) in the cerebrospinal fluid, which suggests an increase in the synthesis of serotonin $[50,60]$. Increasing levels of TRP in humans, serotonin synthesis can be doubled, since the enzyme is only half saturated under normal conditions [61]. The daily intake of $6 \mathrm{~g}$ of TRP can saturate the TRP-hydroxylase and double the rate of serotonin synthesis [61].

As the pathophysiology of depression could be a consequence of alteration of 5-HT activity in many brain structures [62,63], behavioral actions of TRP, obtained in this study, could be mediated by 5-HT. In support of this, report of Wong and Ong [23] in mice who reported that MEL caused an antidepressant-like less potent than TRP was referred, such effect was due to its conversion to 5-HT. Also, TRP supplementation provoked a significant rise in the levels of brain 5-HT in many animal species $[53,64,65]$. Similar augmentation of brain TRP concentration and 5-HT metabolism following TRP injection was shown by many studies [66-68]. Using in vivo micro-dialysis and voltammetry, similar increased functional release of 5-HT in the brain of mammals after an elevated dietary intake of TRP was observed [69]. This 5-HT in the brain would be also the substrate for MEL synthesis, which would be related to the observed antidepressant effects of MEL as suggested by [70].

Otherwise, there is evidence in the literature that the depression is characterized by decreased function in the noradrenergic locus coeruleus, serotoninergic dorsal and median raphe, and dopaminergic ventral tegmental area systems [62]. Also, degeneration of noradrenergic fibers from locus coeruleus has been associated with stressinduced depression in rats [71]. As the MEL receptors are widely distributed in the different parts of brain [72], the antidepressant effects of MEL, probably also that of 
TRP after its conversion to MEL, could be mediated by MEL receptors to modulate neurotransmitter systems [71, 73,74]. In support of this, a strong antidepressant activity induced by agomelatine which is a MEL $\left(\mathrm{MT}_{1}\right.$ and $\mathrm{MT}_{2}$ receptors) agonist and selective serotonin (5-HT2C receptor) [37,42-44] was introduced.

Given the considerations mentioned above, without neglecting other ways of action, it can be assumed that TRP induced antidepressant activity obtained in this study would be the logical consequence of its conversion into MEL which is known to exert the same actions $[17,19]$. In this sense, TRP through MEL, 5-HT or by itself could regulate noradrenergic, serotoninergic and dopaminergic systems in the different parts of the brain to ensure its behavioral effects.

\section{Acknowledgements}

This work was supported by the project PROTARS (D14/ 03) between the University Ibn Toufail Kenitra and CNRST (Morocco), by GDRI Neurosciences (France, Morocco) and the European Neuromed project. Thanks to Dr P. Pévet, of the Institute of Cellular and Integrative Neurosciences, Department of Neurobiology of Rhythms, UPR-3212 CNRS, University of Strasbourg, France, for the gift of the MEL and to Dr D. Boussaoud of UMR INSERM 1106, Aix-Marseille Université, Faculté de Médecine, Marseille, France for support and encouragement.

\section{REFERENCES}

[1] D. C. Klein and R. Y. Moore, "Pineal N-Acetyltransferase and Hydroxyindole Omethyltransferase: Control by the Suprachiasmatic Nucleus," Brain Research, Vol. 174, No. 2, 1979, pp. 245-262. doi:10.1016/0006-8993(79)90848-5

[2] J. Leston, C. Harthé, J. Brun, C. Mottolese, P. Mertens, M. Sindou and B. Claustrat, "Melatonin Is Release in the Third Ventricle in Humans. A Study in Movement Disorders," Neuroscience Letters, Vol. 469, No. 3, 2009, pp. 294-297. doi:10.1016/j.neulet.2009.12.008

[3] B. Claustrat, J. Brun and G. Chazot, "The Basic Physiology and Pathophysiology of Melatonin,” Sleep Medicine Reviews, Vol. 9, No. 1, 2005, pp. 11-24. doi:10.1016/j.smrv.2004.08.001

[4] P. Pévet, "The Role of the Pineal Gland in the Photoperiodic Control of Reproduction in Different Hamster Species," Reproduction Nutrition Development, Vol. 28, No. 2B, 1988, pp. 443-458. doi:10.1051/rnd:19880310

[5] R. J. Wurtman and I. Zhdanova, "Improvement of Sleep Quality by Melatonin,” The Lancet, Vol. 346, No. 8988, 1995, p. 1491. doi:10.1016/S0140-6736(95)92509-0

[6] J. M. Guerrero and R. J. Reiter, "Melatonin-Immune System Relationships," Current Topics in Medicinal Chemistry, Vol. 2, No. 2, 2002, pp. 167-179. doi: $10.2174 / 1568026023394335$
[7] D. E. Blask, L. A. Sauer and C. Dauchy, "Melatonin as a Chronobiotic/Anticancer Agent: Cellular, Biochemical, and Molecular Mechanisms of Action and Their Implications for Circadian-Based Cancer Therapy," Current Topics in Medicinal Chemistry, Vol. 2, No. 2, 2002, pp. 113-132. doi:10.2174/1568026023394407

[8] F. A. Scheer, G. A. Van Montfrans, E. J. Van Someren, G. Mairuhu and R. M. Buijs, "Daily Nighttime Melatonin Reduces Blood Pressure in Male Patients with Essential Hypertension,” Hypertension, Vol. 43, 2004, pp. 192-197. doi:10.1161/01.HYP.0000113293.15186.3b

[9] F. Q. Liang, L. Green, C. Wang, R. Alssadi and B. F. Godley, "Melatonin Protects Human Retinal Pigment Epithelial Cells against Oxidative Stress," Experimental Eye Research, Vol. 78, No. 6, 2004, pp. 1069-1075. doi:10.1016/j.exer.2004.02.003

[10] R. Hardeland, “Antioxidative Protection by MelatoninMultiplicity of Mechanisms from Radical Detoxification to Radical Avoidance,” Endocrine, Vol. 27, No. 2, 2005, pp. 119-130. doi:10.1385/ENDO:27:2:119

[11] V. Srinivasan, "Psychoactive Drugs, Pineal Gland and Affective Disorders," Progress in Neuro-Psychopharmacology \& Biological Psychiatry, Vol. 13, No. 5, 1989, pp. 653-664. doi:10.1016/0278-5846(89)90052-3

[12] M. L. Dubocovich, D. P. Cardinali, P. Delagrange, D. N. Krause, D. Sugden, D. Strosberg and F. Yocca, "Melatonin Receptors,” In: D. Girdlestone, Ed., Compendium of Receptor Characterization and Classification, IUPHAR Media, London, 2000, pp. 271-277.

[13] I. M. McIntyre, F. K. Judd, P. M. Marriott, G. D. Burrows and T. R. Norman, "Plasma Melatonin Levels in Affective States,” International Journal of Clinical Pharmacology Research, Vol. 9, No. 2, 1989, pp. 159-164.

[14] J. Beck-Friis, B. F. Kjellman, B. Aperia, F. Unden, D. von Rosen, J. G. Ljunggren and L. Wetterberg, "Serum Melatonin in Relation to Clinical Variables in Patients with Major Depressive Disorder and a Hypothesis of a Low Melatonin Syndrome,” Acta Psychiatrica Scandinavica, Vol. 71, No. 4, 1985, pp. 319-330. doi:10.1111/j.1600-0447.1985.tb02531.x

[15] R. Brown, J. H. Kocsis, S. Caroff, J. Amsterdam, A. Winokur, P. E. Stokes and A. Frazer, "Differences in Nocturnal Melatonin Secretion between Melancholic Depressed Patients and Control Subjects," American Journal of Psychiatry, Vol. 142, No. 7, 1985, pp. 811-816.

[16] K. Dahl, D. H. Avery, A. J. Lewy, M. V. Savage, G. L. Brengelmann, L. H. Larsen, M. V. Vitiello and P. N. Prinz, "Dim Light Melatonin Onset and Circadian Temperature during a Constant Routine in Hypersomnic Winter Depression,” Acta Psychiatrica Scandinavica, Vol. 88, No. 1, 1993, pp. 60-66. doi:10.1111/j.1600-0447.1993.tb03414.x

[17] F. Z. El Mrabet, S. Ouakki, A. Mesfioui, A. El Hessni and A. Ouichou, "Pinealectomy and Exogenous Melatonin Regulate Anxiety-Like and Depressive-Like Behaviors in Male and Female Wistar Rats," Neurosciene \& Medicine, Vol. 3, 2012, pp. 394-403.

[18] J. L. Workman, Z. M. Weil, C. R. Tuthill and R. J. Nelson, "Maternal Pinealectomy Increases Depressive-Like 
Responses in Siberian Hamster Offspring,” Behavioural Brain Research, Vol. 189, No. 2, 2008, pp. 387-391.

[19] F. Z. El Mrabet, I. Lagbouri, A. Mesfioui, A. El Hessni and A. Ouichou, "The Influence of Gonadectomy on Anxiolytic and Antidepressant Effects of Melatonin in Male and Female Wistar Rats: A Possible Implication of Sex Hormones," Neuroscience \& Medicine, Vol. 3, No. 2, 2012, pp. 162-173. doi:10.4236/nm.2012.32021

[20] B. C. Detanico, A. L. Piato, J. J. Freitas, F. L. Lhullier, M. P. Hidalgo, W. Caumo and E. Elisabetsky, "Antidepressant-Like Effects of Melatonin in the Mouse Chronic Mild Stress Model,” European Journal of Pharmacology, Vol. 607, No. 1-3, 2009, pp. 121-125.

[21] H. Miura, N. Ozaki, M. Sawada, K. Isobe, T. Ohta and T. Nagatsu, “A Link between Stress and Depression: Shifts in the Balance between the Kynurenine and Serotonin Pathways of Tryptophan Metabolism and the Etiology and Pathophysiology of Depression," Stress, Vol. 11, No. 3, 2008, pp. 198-209.

[22] C. Benkelfat, M. Ellenbogen, P. Dean, R. Paimour and S. N. Young, "Mood-Lowering Effect of Tryptophan Depletion: Enhanced Suceptibility in Young Men at Genetic Risk for Major Affective Disorders,” Archives of General Psychiatry, Vol. 51, No. 9, 1994, pp. 687-697.

[23] P. T.-H. Wong and Y. P. Ong, "Acute AntidepressantLike and Antianxiety-Like Effects of tryptophan in Mice,” Pharmacology, Vol. 62, 2001, pp. 151-156. doi:10.1159/000056088

[24] P. L Delgado, D. S. Charney, L. H. Price, G. K. Aghajanian, H. Landis and G. R. Heninger, "Serotonin Function and the Mechanism of Antidepressant Action. Reversal of Antidepressant-Induced Remission by Rapid Depletion of Plasma Tryptophan,” Archives of General Psychiatry, Vol. 47, No. 5, 1990, pp. 411-418. doi:10.1001/archpsyc.1990.01810170011002

[25] L. Booij and A. J. Van der Does, "Cognitive and Serotonergic Vulnerability to Depression: Convergent Findings,” Journal of Abnormal Psychology, Vol. 116, No. 1, 2007, pp. 86-94. doi:10.1037/0021-843X.116.1.86

[26] P. Fusar-Poli, P. Allen, F. Lee, S. Surguladze, N. Tunstall, C. H. Fu, M. J. Brammer, A. J. Cleare and P. K. McGuire, "Modulation of Neural Response to Happy and Sad Faces by Acute Tryptophan Depletion,” Psychopharmacology, Vol. 193, No. 1, 2007, pp. 31-44. doi:10.1007/s00213-007-0757-4

[27] S. D. Paredes, M. P. Terrón, J. Cubero, V. Valero, C. Barriga, R. J. Reiter and A. B. Rodríguez, "Tryptophan Increases Nocturnal Rest and Affects Melatonin and Serotonin Serum Levels in Old Ringdove," Physiology \& Behavior, Vol. 90, No. 4, 2007, pp. 576-582.

[28] A. Ouichou and P. Pévet, "Implication of Tryptophan in the Stimulatory Effect of Delta-Sleep-Inducing Peptide on Indole Secretion from Perifused Rat Pineal Glands,” Neurosignals, Vol. 1, No. 2, 1992, pp. 78-87. doi:10.1159/000109313

[29] J. D. Femstrom, "Tryptophan Availability and Serotonin Synthesis in Brain,” In: G. Huether, Ed., Amino Acid Availability and Brain Function in Health and Disease, NATO ASI Series H: Cell Biology, Springer-Verlag,
Berlin, 1988, pp. 201-206. doi:10.1007/978-3-642-73175-4 12

[30] S. Sánchez, C. L. Sánchez, S. D. Paredes, A. B. Rodriguez and C. Barriga, "The Effect of Tryptophan Administration on the Circadian Rhythms of Melatonin in Plasma and the Pineal Gland of Rats," Journal of Applied Biomedicine, Vol. 6, 2008, pp. 177-186.

[31] S. Esteban, C. Nicolaus, A. Garmundi, R. Victor Rial, A. B. Rodríguez, E. Ortega and C. B. Ibars, "Effect of Orally Administered l-Tryptophan on Serotonin, Melatonin, and the Innate Immune Response in the Rat," Molecular and Cellular Biochemistry, Vol. 267, No. 1-2, 2004, pp. 39-46. doi:10.1023/B:MCBI.0000049363.97713.74

[32] R. C. Zimmermann, C. J. McDougle, M. Schumacher, J. Olcese, J. W. Mason, G. R. Heningerand and L. H. Price, "Effects of Acute Tryptophan Depletion on Nocturnal Melatonin Secretion in Humans," The Journal of Clinical Endocrinology \& Metabolism, Vol. 76, No. 5, 1993, pp. 1160-1164.

[33] R. D. Porsolt, G. Anton, N. Blavet and M. Jalfre, "Behavioural Despair in Rats: A New Model Sensitive to Antidepressant Treatments," European Journal of Pharmacology, Vol. 47, No. 4, 1978, pp. 379-391. doi:10.1016/0014-2999(78)90118-8

[34] N. Benabid and A. Ouichou, "Affective Responses of Early Life Photoperiod in Male Rats,” Neurosciences and Medecine, Vol. 2, No. 3, 2011, pp. 185-191.

[35] N. Benabid, A. Mesfioui and A. Ouichou, "Effects of Photoperiod Regimen on Emotional Behaviour in Two Tests for Anxiolytic Activity in Wistar Rat," Brain Research Bulletin, Vol. 75, No. 1, 2008, pp. 53-59.

[36] L. A. Brotto, A. M. Barr and B. B. Gorzalka, "Sex Differences in Forced-Swim and Open-Field Test Behaviours after Chronic Administration of Melatonin,” European Journal of Pharmacology, Vol. 402, No. 1-2, 2000, pp. 87-93. doi:10.1016/S0014-2999(00)00491-X

[37] V. Micale, A. Arezzi, L. Rampello and F. Drago, "Melatonin Affects the Immobility Time of Rats in the Forced Swim Test: The Role of Serotonin Neurotransmission," European Neuropsychopharmacology, Vol. 16, No. 7, 2006, pp. 538-545. doi:10.1016/j.euroneuro.2006.01.005

[38] Y. Ergün, F. O. Orhan and M. F. Karaaslan, “Combination Therapy of Imipramine and Melatonin: Additive Antidepressant Effect in Mouse Forced Swimming Test," European Journal of Pharmacology, Vol. 591, No. 1-3, 2008, pp. 159-163. doi:10.1016/j.ejphar.2008.06.070

[39] A. V. Shaji and S. K. Kulkarni, "Central Nervous System Depressant Activities of Melatonin in Rats and Mice," Indian Journal of Experimental Biology, Vol. 36, No. 3, 1998, pp. 257-263.

[40] V. Raghavendra, G. Kaur and S. K. Kulkarni, “Anti-Depressant Action of Melatonin in Chronic Forced Swimming-Induced Behavioral Despair in Mice, Role of Peripheral Benzodiazepine Receptor Modulation,” European Neuropsychopharmacology, Vol. 10, No. 6, 2000, pp. 473-481. doi:10.1016/S0924-977X(00)00115-2

[41] D. H. Overstreet, O. Pucilowski, M. C. Retton, P. Delagrange and B. Guardiola-Lemaitre, "Effects of Melatonin Receptor Ligands on Swim Test Immobility,” Neurore- 
port, Vol. 9, No. 2, 1998, pp. 429-453. doi:10.1097/00001756-199801260-00014

[42] N. Barden, E. Shink, M. Labbé, R. Vacher, J. Rochford and E. Mocaër, "Antidepressant Action of Agomelatine (S 20098) in a Transgenic Mouse Model,” Progress in Neuro-Psychopharmacology and Biological Psychiatry, Vol. 29, No. 6, 2005, pp. 908-916. doi:10.1016/j.pnpbp.2005.04.032

[43] M. Bourin, E. Mocaër and R. Porsolt, “AntidepressantLike Activity of S 20098 (Agomelatine) in the Forced Swimming Test in Rodents: Involvement of Melatonin and Serotonin Receptors," Journal of Psychiatry \& Neuroscience, Vol. 29, No. 2, 2004, pp. 126-133.

[44] M. L. Dubocovich, E. Mogilnicka and P. M. Areso, “Antidepressant-Like Activity of the Melatonin Receptor Antagonist, Luzindole (N-0774), in the Mouse Behavioral Despair Test,” European Journal of Pharmacology, Vol. 182, No. 2, 1990, pp. 313-325. doi:10.1016/0014-2999(90)90290-M

[45] L. A. Hilakivi-Clarke, M. J. Durcan, R. G. Lister and M. Linnoila, "Effect of Tryptophan on the Behavior of Nonstressed and Stressed Mice in Porsolt's Swim Test," Pharmacology Biochemistry and Behavior, Vol. 37, No. 2, 1990, pp. 273-276. doi:10.1016/0091-3057(90)90333-D

[46] T. Eriksson and J. Wålinder, "Neuropharmacology: Amitriptyline and Clomipramine Increase the Concentration of Administered L-Tryptophan in the Rat Brain,” Journal of Pharmacy and Pharmacology, Vol. 50, No. 10, 1998, pp. 1133-1137.doi:10.1111/j.2042-7158.1998.tb03324.x

[47] F. Hansen, D. L. de Oliveira, F. U. Í. Amaral, F. S. Guedes, T. J. Schneider, A. C. Tumelero, G. Hansel, K. H. Schmidt, A. C. V. V. Giacomini and F. V. Torres, "Effects of Chronic Administration of Tryptophan with or without Concomitant Fluoxetine in Depression-Related and Anxiety-Like Behaviors on Adult Rat," Neuroscience Letters, Vol. 499, No. 2, 2011, pp. 59-63.

doi:10.1016/j.neulet.2011.05.032

[48] L. A. W. Jans, G. A. H. Korte-Bouws, S. M. Korte and A. Blokland, "The Effects of Acute Tryptophan Depletion on Affective Behaviour and Cognition in Brown Norway and Sprague Dawley Rats," Journal of Psychopharmacology, Vol. 24, No. 4, 2010, pp. 4605-4614.

[49] L. Zhang, L. Guadarrama, A. A. Corona-Morales, A. Vega-Gonzalez, L. Rocha and A. Escobar, "Rats Subjected to Extended L-Tryptophan Restriction during Early Postnatal Stage Exhibit Anxious-Depressive Features and Structural Changes," Journal of Neuropathology \& Experimental Neurology, Vol. 65, No. 6, 2006, pp. 562-570. doi:10.1097/00005072-200606000-00004

[50] S. N. Young and S. Gauthier, "Tryptophan Availability and the Control of 5-HT and Tryptamine Synthesis in Human CNS," Advances in Experimental Medicine and Biology, Vol. 133, 1980, pp. 221-230. doi:10.1007/978-1-4684-3860-4 12

[51] J. D. Schaechter and R. J. Wurtman, "Serotonin Release Varies with Brain Tryptophan Levels,” Brain Research, Vol. 532, No. 1-2, 1990, pp. 203-210. doi:10.1016/0006-8993(90)91761-5

[52] S. N. Young, "Behavioral Effects of Dietary Neurotrans- mitter Precursors: Basic and Clinical Aspects," Neuroscience \& Biobehavioral Reviews, Vol. 20, No. 2, 1996, pp. 313-323. doi:10.1016/0149-7634(95)00022-4

[53] S. Esteban, C. Nicolaus, A. Garmundi, R. V. Rial, A. B. Rodríguez, E. Ortega and C. B. Ibars, "Effect of Orally Administered l-Tryptophan on Serotonin, Melatonin, and the Innate Immune Response in the Rat," Molecular and Cellular Biochemistry, Vol. 267, No. 1-2, 2004, pp. 39-46. doi:10.1023/B:MCBI.0000049363.97713.74

[54] S. Young and G. Anderson, "Factors Influencing Melatonin, 5-Hydroxytryptophol, 5-Hydroxyindolacetic Acid, 5-Hydroxytryptamine and Tryptophan in Rat Pineal Gland,” Neuroendocrinology, Vol. 35, No. 6, 1982, pp. 464-468. doi:10.1159/000123423

[55] S. Sánchez, C. L. Sánchez, S. D. Paredes, A. B. Rodriguez and C. Barriga, "The Effect of Tryptophan Administration on the Circadian Rhythms of Melatonin in Plasma and the Pineal Gland of Rats,” Journal of Applied Biomedicine, Vol. 6, No. 4, 2008, pp. 177-186.

[56] J. Cubero, D. Narciso, V. Valero, M. Rivero, S. D. Peredes, H. Parvez, A. B. Rodriguez and C. Barriga, "The Oral Administration of Tryptophan Improves Nocturnal Rest in Young Animals: Correlation with Melatonin," Biogenic Amines, Vol. 20, No. 1-2, 2006, pp. 53-62.

[57] T. Brzozowski, P. Konturek, S. Konturek, R. Pajdo, W. Bielanski, A. Brzozowki, J. Stachura and E. Hahn, "The Role of Melatonin and L-Tryptophan in Prevention of Acute Gastric Lesions Induced by Stress, Ethanol, Ischemia and Aspirin," Journal of Pineal Research, Vol. 23, No. 2, 1997, pp. 79-89. doi:10.1111/j.1600-079X.1997.tb00339.x

[58] G. Hajak, G. Huether, J. Blanke, M. Blomer, C. Freyer, B. Poeggeler, A. Reimer, A. Rodenbeck, M. Schulz-Varszegi and E. Rüther, "The Influence of Intravenous lTryptophan on Plasma Melatonin and Sleep in Men," Pharmacopsychiatry, Vol. 24, No. 1, 1991, pp. 17-20. doi:10.1055/s-2007-1014427

[59] F. Moreno-Madrid, A. Muñoz-Hoyos, M. Sánchez-Forte, A. Molina-Carballo, M. Macias, G. Escamez, E. Narbona-López and D. Acuña-Castroviejo, "Valoración de un Test de Función Pineal con L-Triptófano en Niños,” Investigación Clínica, Vol. 2, No. 4, 1999, pp. 297-303.

[60] A. E. Harper and J. C. Peters, "Protein Intake Brain Amino Acid and Serotonin Concentrations and Protein Self-Selection," Journal of Nutrition, Vol. 119, No. 5, 1989, pp. 677-689.

[61] S. N. Young, S. Gauthier, G. M. Anderson and W. C. Purdy, "Tryptophan 5-Hydroxyindoleacetic Acid and Indoleacetic Acid in Human Cerebrospinal Fluid: Interrelationships and the Influence of Age, Sex Epilepsy and Anticonvulsant Drugs," Journal of Neurology, Neurosurgery and Psychiatry, Vol. 43, No. 5, 1980, pp. 438-445. doi:10.1136/jnnp.43.5.438

[62] S. Meyers, "Use of Neurotransmitter Precursors for Treatment of Depression," Alternative Medicine Review, Vol. 5, No. 1, 2000, pp. 64-71.

[63] K. J. Ressler and C. B. Nemeroff, "Role of Serotoninergic and Noradrenergic Systems in the Pathophysiology of Depression and Anxiety Disorders," Depression and 
Anxiety, Vol. 12, Suppl. 1, 2000, pp. 2-19. doi:10.1002/1520-6394(2000)12:1+<2::AID-DA2>3.0.C $\underline{0 ; 2-4}$

[64] C. Garau, S. Aparicio, R. V. Rial, M. C. Nicolau and S. Esteban, "Age-Related Changes in Circadian Rhythm of Serotonin Synthesis in Ring Doves: Effects of Increased Tryptophan Ingestion,” Experimental Gerontology, Vol. 41, No. 1, 2006, pp. 40-48. doi:10.1016/j.exger.2005.09.010

[65] G. Huether, B. Poeggeler, L. Adler and E. Ruther, "Effects of Indirectly Acting 5-HT Receptor Agonists on Circulating Melatonin Levels in Rats," European Journal of Pharmacology, Vol. 283, No. 2-3, 1993, pp. 249-254. doi:10.1016/0014-2999(93)90854-B

[66] D. J. Haleem, B. Jabeen and T. Parveen, "Inhibition of Restraint-Induced Anorexia by Injected Tryptophan,” Life Sciences, Vol. 63, No. 14, 1998, pp. 205-212. doi:10.1016/S0024-3205(98)00391-9

[67] M. D. Holder and G. Huether, "Role of Prefeedings Plasma Amino Acid Ratios and Brain Serotonin Levels in CHO and Protein Selection," Physiology \& Behavior, Vol. 47, No. 1, 1990, pp. 113-119. doi:10.1016/0031-9384(90)90048-9

[68] B. H. C. Westerink and J. B. DeVries, "Effect of Precursor Loading on the Synthesis Rate and Release of Dopamine and Serotonin in the Striatum. A Microdialysis Study in Conscious Rats," Journal of Neurochemistry, Vol. 56, No. 1, 1991, pp. 228-233. doi:10.1111/j.1471-4159.1991.tb02585.x
[69] M. C. Boadle-Biber, "Regulation of Serotonin Synthesis," Progress in Biophysics and Molecular Biology, Vol. 60, No. 1, 1993, pp. 1-15.doi:10.1016/0079-6107(93)90009-9

[70] S. D. Paredes, M. P. Terrón, A. M. Marchena, C. Barriga, J. A. Pariente, R. J. Reiter and A. B. Rodríguez, "Effect of Exogenous Melatonin on Viability, Ingestion Capacity, and Free-Radical Scavenging in Heterophils from Young and Old Ringdove (Streptopelia risoria)," Molecular and Cellular Biochemistry, Vol. 304, No. 1-2, 2007, pp. 305-314. doi:10.1007/s11010-007-9513-7

[71] I. Kitayama, S. Nakamura and T. Yaga, "Degeneration of Locus Coeruleus Axons in Stress-Induced Depression Model,” Brain Research Bulletin, Vol. 35, No. 5-6, 1994, pp. 573-580. doi:10.1016/0361-9230(94)90171-6

[72] M. L. Dubocovich, M. I. Masana and S. Benloucif, “Molecular Pharmacology and Function of Melatonin Receptor Subtypes,” In: J. Olcese, Ed., Melatonin after Four Decades: An Assessment of Its Potential, Kluwer Academy/Plenum Publishers, New York, 2000, pp. 181-190.

[73] R. E. Rosenstein and D. P. Cardinali, "Melatonin Increases in Vivo Gaba Accumulation in Rat Hypothalamus, Cerebellum, Cerebral Cortex and Pineal Gland,” Brain Research, Vol. 398, No. 2, 1986, pp. 403-406. doi:10.1016/0006-8993(86)91505-2

[74] F. Xu, J. C. Li, K. C. Ma and M. Wang, "Effects of Melatonin on Hypothalamic Gamma-Aminobutyric Acid, Aspartic Acid, Glutamic Acid, Beta-Endorphin and Serotonin Levels in Male Mice,” Neurosignals, Vol. 4, No. 4 1995, pp. 225-231. doi:10.1159/000109446 